\title{
SAAV2152 is a single-stranded DNA binding protein: the third SSB in Staphylococcus aureus
}

\author{
Yen-Hua Huang ${ }^{1}$ and Cheng-Yang Huang ${ }^{1,2}$ \\ ${ }^{1}$ School of Biomedical Sciences, Chung Shan Medical University, Taichung City, Taiwan \\ ${ }^{2}$ Department of Medical Research, Chung Shan Medical University Hospital, Taichung City, Taiwan \\ Correspondence to: Cheng-Yang Huang, email: cyhuang@csmu.edu.tw \\ Keywords: SsbA; sSDNA; PriA; NSC5426; novel SSB; Immunology \\ Received: December 20, 2017 Accepted: January 31, 2018 Epub: February 05, 2018 Published: April 17, 2018 \\ Copyright: Huang et al. This is an open-access article distributed under the terms of the Creative Commons Attribution License 3.0 \\ (CC BY 3.0), which permits unrestricted use, distribution, and reproduction in any medium, provided the original author and source \\ are credited.
}

\section{ABSTRACT}

Single-stranded DNA-binding proteins (SSBs) play crucial roles in DNA replication, repair, and recombination. Unlike $E$. coli, which contains only one type of SSB (EcSSB), some bacteria have two paralogous SSBs, namely, SsbA and SsbB. In this study, we found the third SSB-like protein in Staphylococcus aureus, SAAV2152, which was designated as SaSsbC. SaSsbC is a protein of 131 amino acids and shares $38 \%$, $36 \%$, and $33 \%$ sequence identity to SaSsbB, SaSsbA, and EcSSB, respectively. Gene map analysis showed that unlike the $E$. coli ssb gene, which is adjacent to uvrA gene, the $S$. aureus SSb gene SAAV2152 is flanked by the putative $S c e D$, the putative $Y w p F$, and fabZ genes. A homology model showed that SaSsbC consists of the classic oligonucleotide/oligosaccharide-binding fold at the $\mathbf{N}$-terminus. At the C-terminus, SaSsbC did not exhibit sequence similarity to that of EcSSB. Electrophoretic mobility shift analysis showed that SaSsbC formed a single complex with ssDNA of different lengths. Mutational analysis revealed that Tyr36, Tyr47, Phe53, and Tyr81 in SaSsbC are at positions that structurally correspond to the important residues of EcSSB for binding to sSDNA and are also critical for SaSsbC to bind SSDNA. Unlike EcSSB, which can stimulate EcPriA, SaSsbC did not affect the activity of SaPriA. In addition, SaSsbA inhibitor 9-methyl-2,3,7-trihydroxy-6-fluorone (NSC5426) could inhibit the SSDNAbinding activity of SaSsbC with $\mathrm{IC}_{50}$ of $78 \mu \mathrm{M}$. In conclusion, this study has identified and characterized SAAV2152 as a kind of SSB, and further research can directly focus on determining its actual physiological role in $S$. aureus.

\section{INTRODUCTION}

Single-stranded DNA-binding proteins (SSBs) play crucial roles in DNA metabolic processes, such as DNA replication, repair, and recombination in both prokaryotes and eukaryotes $[1,2]$. During these reactions, SSB is required to maintain the transient unwinding of duplex DNA in the single-stranded state. SSB binds and protects susceptible ssDNA from nucleases and chemical attacks [3]. SSB binds to ssDNA with high affinity regardless of sequence. Four distinct DNA-binding domains in SSBs have been identified, namely, the oligonucleotide/ oligosaccharide-binding fold (OB fold), the K homology domain, the RNA recognition motif, and the whirly domain [4]. Most but not all bacterial SSBs are active as homotetramers, in which four OB folds form a DNAbinding domain $[5,6]$. SSB from the bacterial phylum Deinococcus-Thermus functions as a homodimer, in which each monomer contains two OB folds linked by a conserved spacer sequence $[7,8]$. In addition to DNA binding, SSB also binds to many DNA-binding proteins that constitute the SSB interactome $[2,9,10]$.

The functions of SSB have been studied extensively in Escherichia coli. E. coli SSB (EcSSB) has two major ssDNA binding modes [11]. The binding mode is dependent on the concentrations of protein and salt in the solution. EcSSB consists of an N-terminal ssDNAbinding/oligomerization domain and a flexible C-terminal 
protein-protein interaction domain $(\mathrm{SSBc})[2,4]$. SSBc can be further subdivided into two sub-domains, as follows: a long proline- or glycine-rich hinge, also known as the intrinsically disordered linker; and the highly conserved acidic tail of the last six C-terminal amino acid residues of SSB (DDDIPF) [2, 12]. This C-terminal acidic tail of SSB is essential for binding to more than a dozen different proteins [2] and can stimulate the activities of some of these proteins $[13,14]$. SSBc, not only the C-terminal acidic tail, can also interact with the OB fold and regulate the ssDNA-binding activity of SSB itself $[15,16]$.

Unlike E. coli, which contains only one type of SSB, several bacteria have two paralogous SSBs, namely, SsbA and SsbB [17-19]. SsbA shares strong sequence similarity with the N-terminal DNA-binding domain and the C-terminal acidic tail of SSB and is thus referred to as a counterpart of EcSSB. Bacillus subtilis SsbA $(\mathrm{BsSsbA})$ is a protein of 172 aa, essential for genome maintenance [20]. In contrast to BsSsbA, the 113-aaprotein $\mathrm{BsSsbB}$ is specialized for transformational recombination. Although crystal structures suggest that SsbA binds ssDNA in a manner similar to SsbB [21, 22], their DNA-binding properties are different. BsSsbB binds to ssDNA with lesser affinity than BsSsbA, whereas Streptomyces coelicolor $\mathrm{SsbB}(\mathrm{ScSsbB})$ exerts greater DNA-binding affinity than ScSsbA [21-23]. In addition, BsSsbB and ScSsbB but not Streptococcus pneumonia SsbB (SpSsbB), lack the C-terminal acidic tail of SSB for protein-protein interactions. Thus, SsbBs from different organisms may exhibit different protein-protein interaction specificities.

PriA helicase is utilized during replication restart to reload the replicative DnaB helicase back onto the chromosome [24-26]. Fuelled by the binding and hydrolysis of ATP, PriA acts with other primosomal proteins and separates double-stranded DNA (dsDNA) into their complementary single strands [27-29]. On its own, PriA is a poor helicase and might need other accessory proteins, such as PriB and SSB, to stimulate helicase activity [13, 14]. However, the main SSB of Staphylococcus aureus (SaSsbA) does not stimulate SaPriA [30]. Only SaDnaD enhances the ATPase activity of SaPriA [31]. Thus, the manner by which $\mathrm{SaSsbA}$ and $\mathrm{SaSsbB}$ participate in the SaPriA-directed primosome assembly and in the DNA replication restart process is still unclear.

In this study, we found and identified the third SSBlike protein in S. aureus. This novel SSB, designated as $\mathrm{SaSsbC}$, has been cloned, overexpressed, and biochemically characterized. Results from the sequence alignment, structural modeling, and mutational analyses indicated a similar ssDNA-binding mode between SaSsbC and EcSSB. Although the C-terminal domain of SaSsbC exhibits no sequence similarity with that of EcSSB, $\mathrm{SaSsbC}$ is a typical SSB protein in many aspects.

\section{RESULTS}

\section{The third ssb gene}

Some bacteria have two paralogous SSBs (SsbA and SsbB) [19]. They have similar nucleotide sequence with $E$. coli SSB. Three $S$. aureus ssb genes (SAAV0334, $S A A V 0835$, and SAAV2152) were found after searching through the National Center for Biotechnology Information (NCBI). These three SSBs share an overall $36 \%$ sequence identity and are mostly conserved in the first 110 aa (i.e. the N-terminal domain). Based on similarity with BsSsbA and BsSsbB, SAAV0334 encodes SaSsbA of 167 aa, whereas SAAV0835 encodes SaSsbB of 141 aa. SAAV2152 encodes a protein of 131 aa. This SSB was designated as $\mathrm{SaSsbC}$ in this study (Figure 1).

\section{Sequence analysis of SaSsbC}

The amino acid sequence of SaSsbC shares 38\%, $36 \%, 33 \%$, and $32 \%$ identity to that of SaSsbB, SaSsbA, $\mathrm{EcSSB}$, and KpSSB, respectively (Figure 1), with $\mathrm{SaSsbC}$ being the shortest one. Analysis of SaSsbC by RPS-BLAST showed the presence of a putative OB-fold domain that is common to all known SSBs. Figure 2A shows the alignment consensus of 698 sequenced SSB homologs by ConSurf [32], revealing the degree of variability at each position along the primary sequence. The amino acid residues in the C-terminal region of $\mathrm{SaSsbC}$ are variable. In the EcSSB-ssDNA complex [5], four essential aromatic residues, Trp40, Trp54, Phe60, and Trp88, conserved in most SSB families as Phe/Tyr/Trp, participate in ssDNA binding via stacking interactions. The corresponding residues in SaSsbC are Tyr36, Tyr47, Phe53, and Tyr81. No Trp residue was observed in $\mathrm{SaSsbC}$ (Figure 1). The protein sequence analogous to the C-terminal tail DDDIPF in EcSSB involved in proteinprotein interaction is HDLLEI in SaSsbC. Thus, similar to $\mathrm{ScSsbB}$ [21], SaSsbC lacks the acidic tail that is conserved in all main SSB sequences. The evolutionary tree for SSBs with $\mathrm{SaSsbC}$ showed that they could be classified into at least 6 groups (Figure 2B). Although $\mathrm{SaSsbC}$ and SpSsbA share $34 \%$ identity, they were classified into different phylogenetic groups by SmartBlast.

\section{Analysis of the $s s b$ gene $S A A V 2152$}

Figure 3 shows the gene map of $S$. aureus chromosomal region with the third $s s b$ gene, which is flanked by the putative $S c e D$, the putative $Y w p F$, and $f a b Z$ genes, which code for a transglycosylase (231 aa), a hypothetical protein (167 aa), and a $\beta$-hydroxyacyl-ACP dehydratase (146 aa), respectively. $S$. aureus and $B$. subtilis main $s s b$ genes are flanked by $r p s F$ and $r p s R$ and are controlled by the SOS response [19], whereas the gene regulation of the $s s b$ gene SAAV2152 coding for SaSsbC is almost unknown. 


\section{Purification of SaSsbC}

SAAV2152 coding for the putative SSB-like protein designated as SaSsbC in this study was PCR-amplified using the genomic DNA of $S$. aureus subsp. aureus ED98 as template. This amplified gene was then ligated into the pET21b vector for protein expression. SaSsbC with a His tag was heterologously overexpressed in E. coli and then purified from the soluble supernatant by $\mathrm{Ni}^{2+}$-affinity chromatography. Pure protein was obtained in this single chromatographic step with an elution of
Buffer A and dialyzed against a dialysis buffer (Buffer B). Approximately $>15 \mathrm{mg}$ of purified protein was obtained from $1 \mathrm{~L}$ of $E$. coli cell culture.

\section{SaSsbC bound to ssDNA}

Given that the sequence analysis may indicate $\mathrm{SaSsbC}$ as a kind of SSB, we attempted to test whether $\mathrm{SaSsbC}$ has ssDNA-binding activity. We studied the binding of SaSsbC to ssDNA of different lengths with different protein concentrations using EMSA (Figure 4).

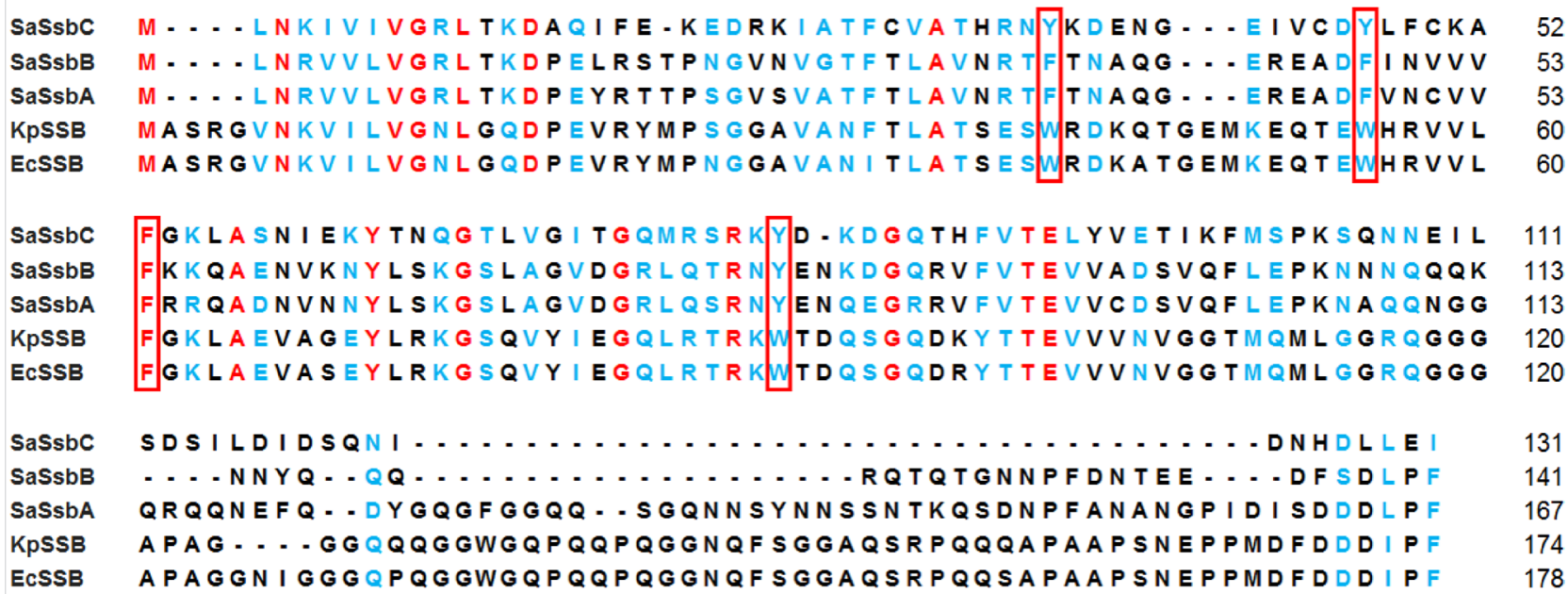

Figure 1: Multiple amino acid sequence alignment of SSB proteins. Sequence alignment of SaSsbC, SaSsbB, SaSsbA, KpSSB, and EcSSB was generated by CLUSTALW2. Identical amino acid residues are colored in red. Amino acid residues with similar properties judged by CLUSTALW2 are colored in light blue. The essential aromatic residues involved in ssDNA binding are boxed. The C-terminal domains of these SSBs are not conserved.

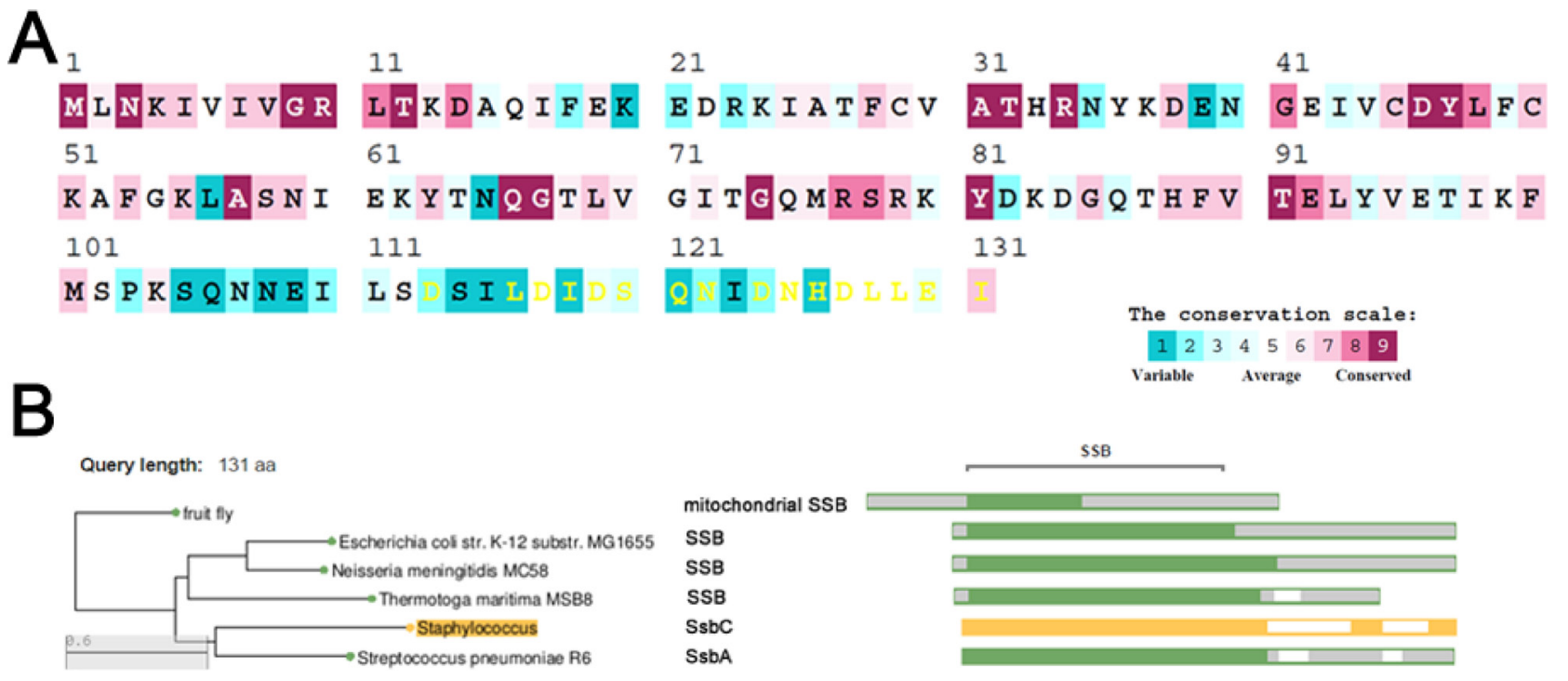

Figure 2: Sequence analysis of SaSsbC. (A) An alignment consensus of 698 sequenced SSB homologs by ConSurf reveals the degree of variability at each position along the primary sequence. Highly variable amino acid residues are colored teal, whereas highly conserved amino acid residues are burgundy. A consensus sequence was established by determining the most commonly found amino acid residue at each position relative to the primary sequence of SaSsbC. (B) The evolutionary tree of SSBs with SaSsbC was generated by SmartBlast. They could be classified into at least 6 groups of SSB family. 
EMSA is a well-established approach in studies of molecular biology, allowing the detection of the distinct protein-DNA complex(es) [33]. When we incubated SaSsbC with dT20, no significant band shift was observed (Figure 4A), indicating that SaSsbC could not form a stable complex with dT20. We further tested dT25-60 to bind to SaSsbC. In contrast with dT20, longer dT homopolymers, such as dT25-60, produced a very significant band shift (Figure 4; C, complex). These findings confirm the ssDNA-binding activity of SaSsbC, which was strong enough to form a stable protein-DNA complex in solution. The binding ability of SaSsbC to dT20, dT30, and dT40 in the presence of $0.4 \mathrm{M} \mathrm{NaCl}$ was also analyzed (Figure 5). To compare the binding abilities of SaSsbC with ssDNA of different lengths, as well as the salt effect on the ssDNA-binding abilities of SaSsbC, we calculated the midpoint values for input ssDNA binding from the titration curves of EMSA, and the [Protein $]_{50}$ values were quantified using linear interpolation from the protein concentration (Table 1). The ssDNA-binding ability of SaSsbC correlated with the length of ssDNA, that is, with longer ssDNA corresponded to higher binding affinity. In addition, salt suppressed the binding of SaSsbC to ssDNA. For example, The $[\mathrm{SaSsbC}]_{50}$ for dT40 binding was $225 \pm 15 \mathrm{nM}$, which was about twofold lower than in the presence of $0.4 \mathrm{M} \mathrm{NaCl}(418 \pm 26 \mathrm{nM})$.

\section{Oligomeric state of SaSsbC in solution}

The oligomeric state of purified SaSsbC was analyzed by gel filtration chromatography (Figure 6A). The native molecular mass of SaSsbC was estimated to be $64 \mathrm{kDa}$, which is approximately four times the molecular mass of a SaSsbC monomer (15 kDa). Thus, SaSsbC in solution is a stable tetramer like SaSsbA [30], EcSSB [5], PaSSB [34], StSSB [35], and KpSSB [36].

To further substantiate the observation made from gel filtration chromatography, chemical cross-linking of SaSsbC using glutaraldehyde was performed (Figure 6B). $2.5 \mu \mathrm{M}$
$\mathrm{SaSsbC}$ was incubated with increasing concentrations of glutaraldehyde $(0.1 \%-5 \%)$ at $4^{\circ} \mathrm{C}$ for $30 \mathrm{~min}$. At these concentrations, the tetrameric form of SaSsbC was observed. The glutaraldehyde cross-linking result showed that $\mathrm{SaSsbC}$ occurred as a tetramer in solution, consistent with that analyzed using gel filtration chromatography.

\section{SaSsbC cannot bind dsDNA}

Sequence similarity (Figure 1) and ssDNA-binding analysis (Figure 4) indicated that SaSsbC is a type of SSB, similar to SaSsbA and EcSSB. To investigate whether SaSsbC binds dsDNA, the 25-bp dsDNA substrate for EMSA was prepared by annealing oligonucleotides PS4 and PS3, of which one DNA strand was radiolabeled. No band shift was observed when $\mathrm{SaSsbC}$ was incubated with PS4/PS3. The absence of band shift indicated that SaSsbC could not form a stable complex with this DNA substrate during electrophoresis (Figure 7A). We further tested whether SaSsbC binds to dsDNA with ssDNA overhang of 5-25 mer dT. SaSsbC could not form a stable complex with the following DNA substrates: PS4/PS3-dT5, PS4/PS3dT10, PS4/PS3-dT15, and PS4/PS3-dT20 (Figure 7B). However, SaSsbC could form a stable complex with PS4/ PS3-dT25 (Figure 7C). Given that SaSsbC can bind to ssDNA dT25 (Figure 4B) but not to dT20 (Figure 4A), we hypothesized that SaSsbC can likely bind to PS4/ PS3-dT25 because of the dT25 tail in PS4/PS3-dT25. In addition, the $[\mathrm{SaSsbC}]_{50}$ for PS4/PS3-dT25 binding was $232 \pm 18 \mathrm{nM}$, a value similar to that for dT25 binding (234 $\pm 18 \mathrm{nM}$ ). Thus, SaSsbC cannot bind to dsDNA on the basis of the EMSA results.

\section{SaSsbC can bind ssDNA-containing forked DNA}

To investigate whether SaSsbC binds to forked DNA, we prepared M1/M2-M3 forked DNA substrate for EMSA by annealing oligonucleotides M1 (90 bp), M2 (78 $\mathrm{bp})$, and M3 (28 bp), of which M2 was radiolabeled. This

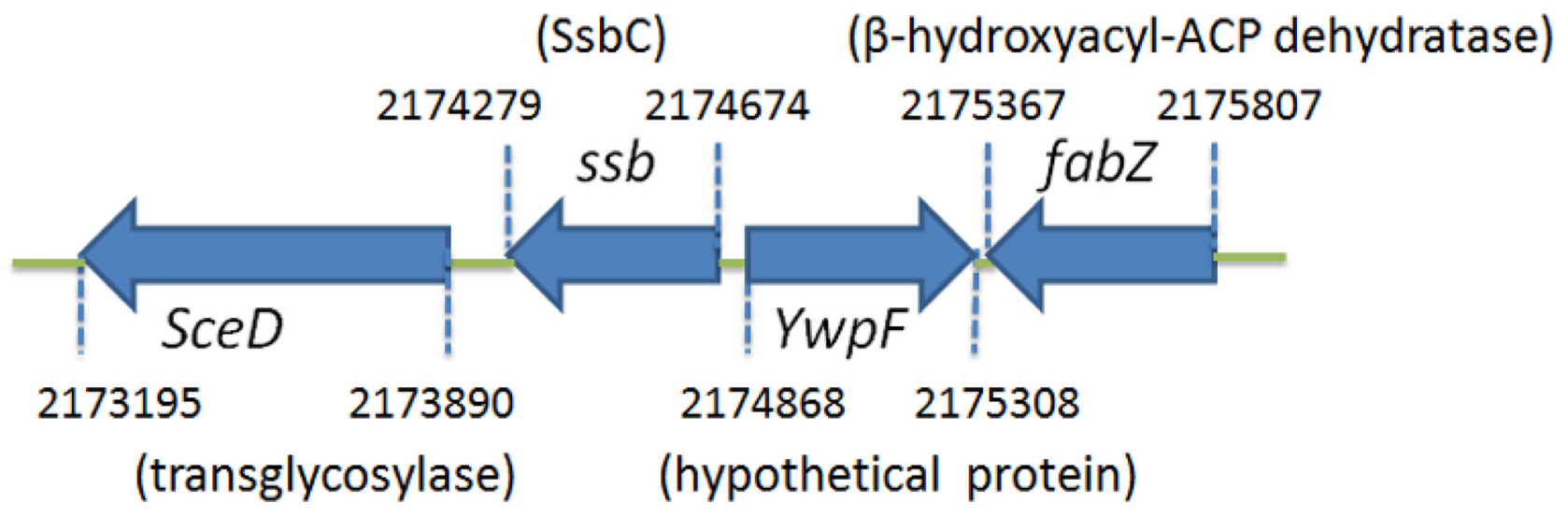

Figure 3: Gene map of $\boldsymbol{S}$. aureus chromosomal region with the ss $\boldsymbol{b}$ gene $\boldsymbol{S A A V 2 1 5 2}$. The gene $S A A V 2152$ coding for SaSsbC maps from the 2174279 to 2174674 nt of the $S$. aureus genome. This ssb gene is flanked by the putative $S c e D$, the putative $Y w p F$, and $f a b Z$ genes, coding for a transglycosylase (231 aa), a hypothetical protein (167 aa), and a $\beta$-hydroxyacyl-ACP dehydratase (146 aa), respectively. 
DNA substrate will produce a 40-bp ssDNA region when completely annealed. SaSsbC could form a stable complex with M1/M2-M3 forked DNA with $[\text { SaSsbC }]_{50}$ of 190 $\pm 18 \mathrm{nM}$ (Figure 8). This binding constant was slightly higher than that for dT40 homopolymer binding (225 \pm $15 \mathrm{nM})$. We also tested whether SaSsbC binds to forked DNA with shorter ssDNA (S1/M2-M3; S1, 70 bp). This DNA substrate will produce a 20 -bp ssDNA region when completely annealed. No band shift was observed when $\mathrm{SaSsbC}$ was incubated with S1/M2-M3 forked DNA (data not shown). Thus, we hypothesized that SaSsbC can likely bind to M1/M2-M3 forked DNA because of the 40-bp tail in this DNA.

\section{SaSsbC cannot stimulate the ATPase activity of} SaPriA

On its own, PriA is a poor helicase in vitro [37]. Gram-negative EcPriA activity can be significantly stimulated by EcPriB and EcSSB [13, 14]. SaPriA activity can be stimulated by SaDnaD [31]; however, unlike EcSSB, SaSsbA cannot stimulate SaPriA [30]. Whether or not SaSsbC can enhance SaPriA activity is still unknown. To investigate the possible effect of SaSsbC, we performed ATPase assay for SaPriA. SaDnaD [31] and KpSSB [30], which are known to stimulate SaPriA activity, were used as positive controls. As shown in Figure 9, SaPriA could

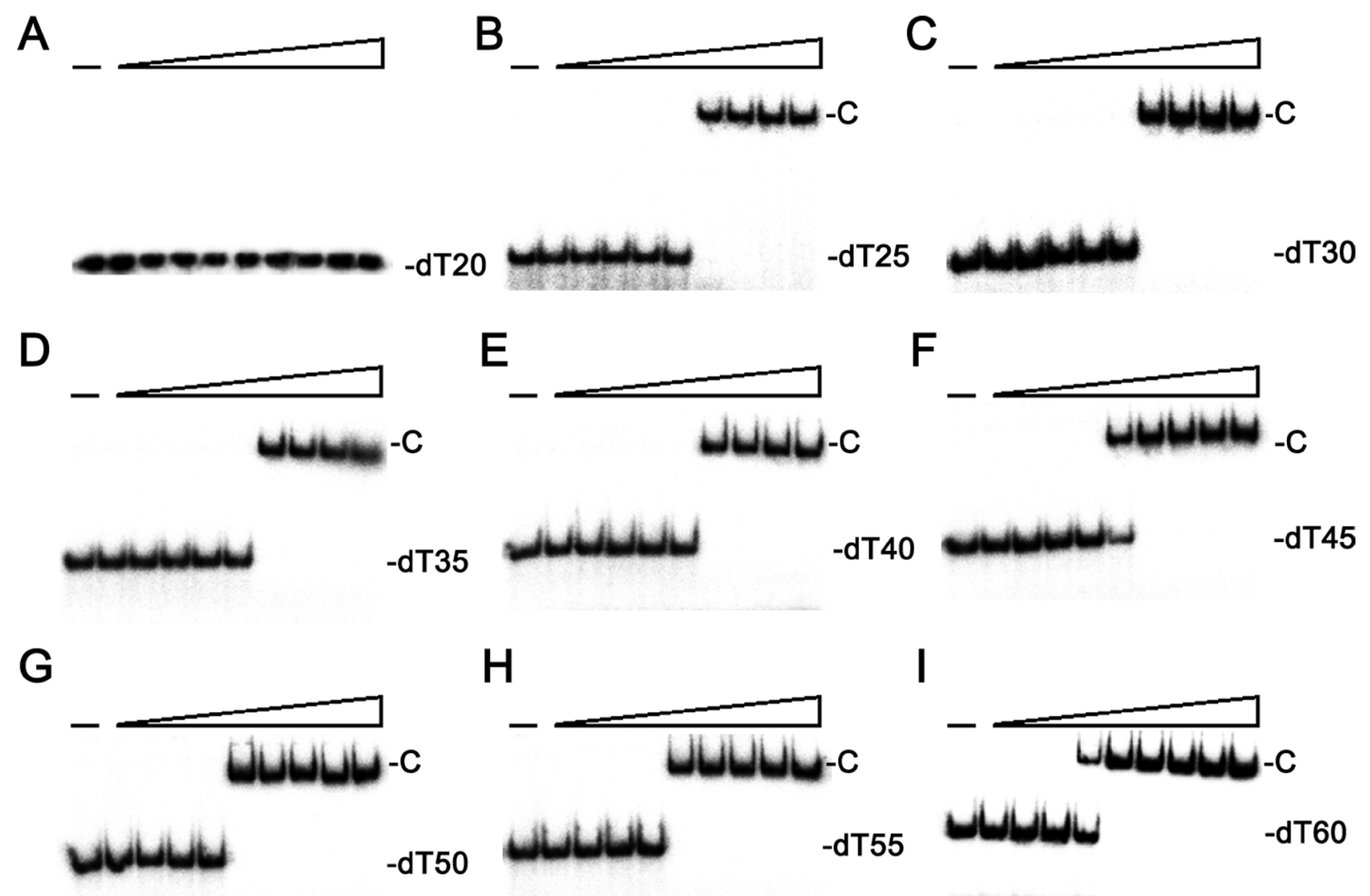

Figure 4: EMSA of SaSsbC. Protein (0, 0.01, 0.02, 0.039, 0.078, 0.1563, 0.3125, 0.625, 1.25, and $2.5 \mu \mathrm{M}$; tetramer) was incubated with $1.7 \mathrm{nM}$ of (A) dT20, (B) dT25, (C) dT30, (D) dT35, (E) dT40, (F) dT45, (G) dT50, (H) dT55, or (I) dT60, and then analyzed by EMSA.

A
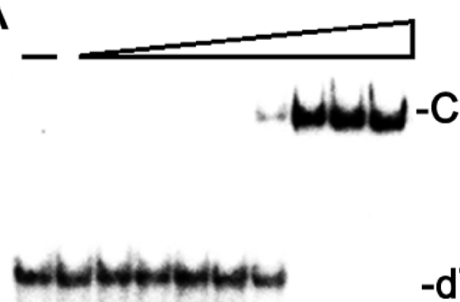

B

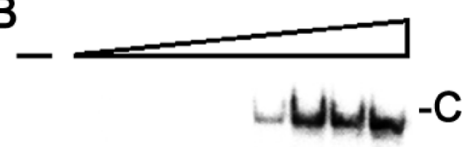

$-\mathrm{dT} 40$

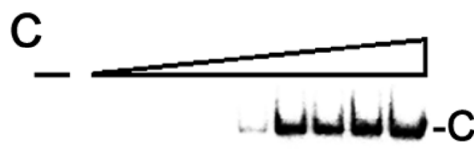

wholutwo

Figure 5: EMSA of SaSsbC in the presence of $\mathbf{0 . 4}$ M NaCl. Protein $(0,0.01,0.02,0.039,0.078,0.1563,0.3125,0.625,1.25$, and $2.5 \mu \mathrm{M}$; tetramer) was incubated with $1.7 \mathrm{nM}$ of (A) dT30, (B) dT40, or (C) dT50 in $20 \mathrm{mM}$ Tris $-\mathrm{HCl}(\mathrm{pH} 8.0)$ and $400 \mathrm{mM} \mathrm{NaCl}$. The resultant solution was then analyzed by EMSA. 
Table 1: The [Protein $]_{50}$ values of SaSsbC as analyzed by EMSA

\begin{tabular}{lc}
\hline DNA & [Protein $_{50}(\mathbf{n M})$ \\
\hline dT20 & $\mathrm{ND}$ \\
dT25 & $234 \pm 18$ \\
dT30 & $230 \pm 8$ \\
dT30 (with 0.4 M NaCl) & $420 \pm 26$ \\
dT35 & $220 \pm 16$ \\
dT40 & $225 \pm 15$ \\
dT40 (with 0.4 M NaCl) & $418 \pm 26$ \\
dT45 & $125 \pm 9$ \\
dT50 & $117 \pm 10$ \\
dT50 (with 0.4 M NaCl) & $208 \pm 18$ \\
dT55 & $115 \pm 7$ \\
dT60 & $102 \pm 6$ \\
PS4/PS3 & $\mathrm{ND}$ \\
PS4/PS3-dT5 & $\mathrm{ND}$ \\
PS4/PS3-dT10 & $\mathrm{ND}$ \\
PS4/PS3-dT15 & $\mathrm{ND}$ \\
PS4/PS3-dT20 & $\mathrm{ND}$ \\
PS4/PS3-dT25 & $232 \pm 18$ \\
M1/M2-M3 & $190 \pm 18$ \\
S1/M2-M3 & $\mathrm{ND}$ \\
\hline Protn & \\
\hline
\end{tabular}

[Protein $]_{50}$ was calculated from the titration curves of EMSA by determining the concentration of the protein (tetramers) needed to achieve the midpoint value for input DNA binding. Errors are standard deviations determined by three independent titration experiments.

hydrolyze ATP on its own; however, no effect was found on SaPriA activity when acting with SaSsbC. To exclude the possible effect of a His tag, we used a tag-free $\mathrm{SaSsbC}$ for this assay (Figure 9). Thus, similar to SaSsbA, SaSsbC does not affect the activity of SaPriA.

\section{Structural modeling of SaSsbC}

The crystal structure of $\mathrm{SaSsbC}$ is yet to be determined. We modeled SaSsbC by homology modeling using SWISS-MODEL (http://swissmodel.expasy.org/) [38]. The N-terminal domain of SaSsbA (PDB entry 5GXT) [30] was the first hit suggested as a template by the program. The structural model of SaSsbC (aa 1-103) revealed an OB-fold domain (Figure 10A) similar to that of SaSsbA (Figure 10B) and EcSSB (Figure 10C), with the core of the OB-fold possessing a $\beta$-barrel capped by an $\alpha$-helix. In the EcSSB-ssDNA complex (Figure 10C), four essential aromatic residues, $\operatorname{Trp} 40, \operatorname{Trp} 54$, Phe60, and Trp88, participate in ssDNA binding via stacking interactions [5]. The corresponding residues in $\mathrm{SaSsbC}$ are Tyr36, Tyr47, Phe53, and Tyr81, which may play a similar role in ssDNA binding as those in EcSSB (Figure 10D).

\section{Mutational analysis}

On the basis of the proposed structural model of $\mathrm{SaSsbC}$ (Figure 10) and in comparison with the EcSSBssDNA complex structure, the four aromatic residues (i.e. Tyr36, Tyr47, Phe53, and Tyr81) located on the protein surface may be involved in ssDNA binding via stacking interactions. These residues in $\mathrm{SaSsbC}$ allow nucleic acids to wrap around the whole $\mathrm{SaSsbC}$, similar to that in EcSSB-ssDNA complex [5]. According to the EcSSB- 
ssDNA complex structure, we manually superimposed the location of ssDNA with the structure model of SaSsbC (Figure 10D). To test whether the proposed model can possibly be used to form the SaSsbC-ssDNA complex, alanine substitution mutants (i.e., Y36A, Y47A, F53A, and Y81A) were conducted and analyzed by EMSA (Figure 11). The [Protein $]_{50}$ values for the binding of these $\mathrm{SaSsbC}$ variants to dT50 are summarized in Table 2. These $\mathrm{SaSsbC}$ mutants have [Protein $]_{50}$ values that were higher than that of the wild-type SaSsbC. The mutational effect on the ssDNA binding activity of SaSsbC followed the order Y81A > F53A > Y47A > Y36A; results of Y36A and Y47A were not very significant. Thus, SaSsbC may bind ssDNA in a manner similar to that in EcSSB.

\section{Thermostability}

SSB proteins have high thermostability even those coming from psychrophilic bacteria [39]. To investigate the stability of SaSsbC at elevated temperatures, we performed indirect thermostability experiments (Figure 12). The thermostability of SaSsbA was also analyzed. Incubation of SaSsbA and $\mathrm{SaSsbC}$ at 40,60 , and $80^{\circ} \mathrm{C}$ for 30 min showed no loss in binding activity to dT30. The activity of $\mathrm{SaSsbA}$ incubated for $30 \mathrm{~min}$ decreased by $60 \%$ at $100^{\circ} \mathrm{C}, 35 \%$ at $95^{\circ} \mathrm{C}, 15 \%$ at $90^{\circ} \mathrm{C}$, and $2 \%$ at $85^{\circ} \mathrm{C}$. The activity of SaSsbC incubated for $30 \mathrm{~min}$ decreased by $70 \%$ at $100^{\circ} \mathrm{C}, 40 \%$ at $95^{\circ} \mathrm{C}, 20 \%$ at $90^{\circ} \mathrm{C}$, and $2 \%$ at $85^{\circ} \mathrm{C}$. Given that the activity of EcSSB decreased by $50 \%$ after $30 \mathrm{~min}$ incubation at $95^{\circ} \mathrm{C}$ [39], we determined that the thermostability of these SSBs followed the order $\mathrm{SaSsbA}>\mathrm{SaSsbC}>\mathrm{EcSSB}$. Thus, similar to EcSSB and other SSBs, SaSsbC exhibits high thermostability.

\section{SaSsbA inhibitor NSC5426 inhibits SaSsbC}

Some compounds are known to inhibit ssDNAbinding activity of SaSsbA [40]. For example, ssDNAbinding ability of SaSsbA can be completely suppressed by the presence of $100 \mu \mathrm{M}$ 9-methyl-2,3,7-trihydroxy-6-
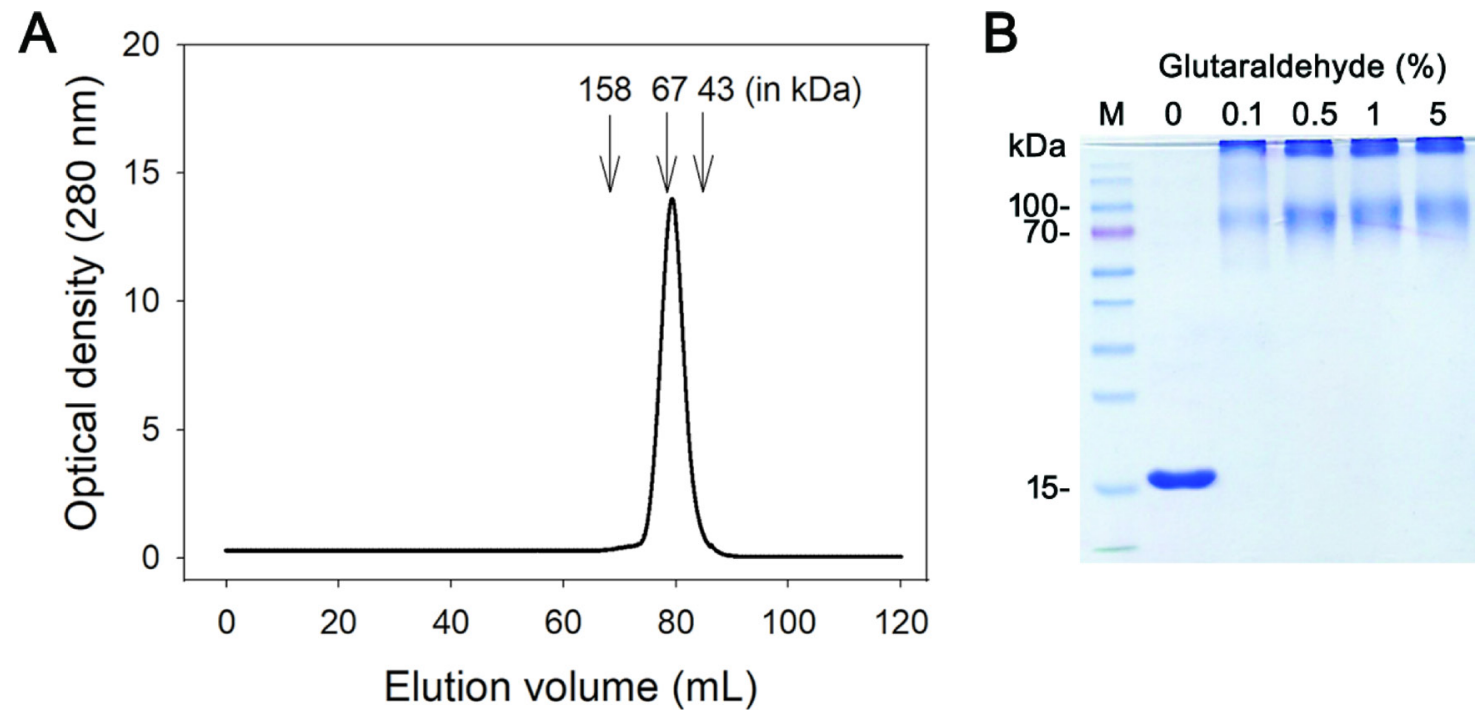

Figure 6: Oligomeric state of purified SaSsbC in solution. (A) Gel filtration chromatographic analysis (Superdex 200 prep grade column) of purified SaSsbC. The column was calibrated with proteins of known molecular masses: thyroglobulin (670 kDa), $\gamma$-globulin $(158 \mathrm{kDa})$, albumin $(67 \mathrm{kDa})$, ovalbumin $(43 \mathrm{kDa})$, chymotrypsinogen A (25 kDa) and ribonuclease A $(13.7 \mathrm{kDa})$. The corresponding peak shows the eluted SaSsbC. (B) Glutaraldehyde cross linking of SaSsbC. SaSsbC $(2.5 \mu \mathrm{M})$ was incubated with increasing concentrations of glutaraldehyde $(0.1 \%$ to $5 \%)$ at $4^{\circ} \mathrm{C}$ for $30 \mathrm{~min}$. Coomassie Blue-stained SDS-PAGE of the resulting samples and molecular mass standards are shown.
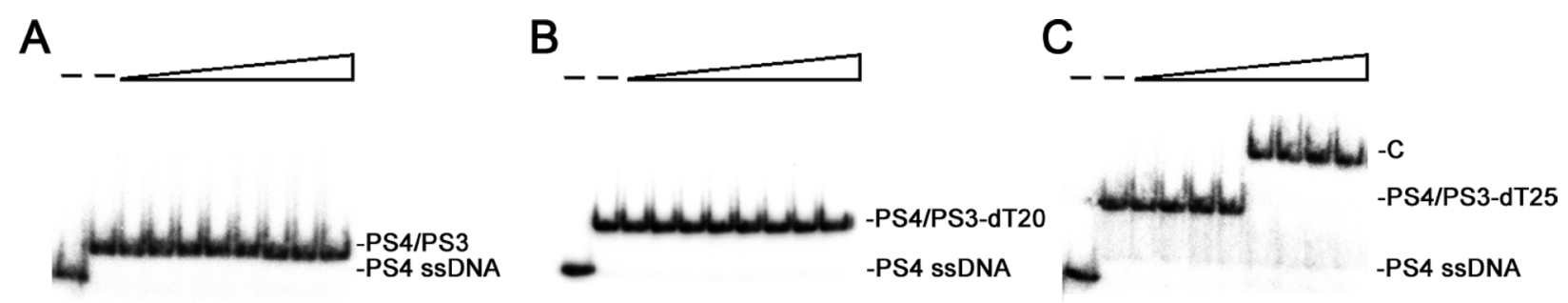

Figure 7: Binding analysis of SaSsbC to dsDNA. Protein $(0,0,0.02,0.039,0.078,0.1563,0.3125,0.625,1.25$, and $2.5 \mu \mathrm{M}$; tetramer) was incubated with $1.7 \mathrm{nM}$ of (A) PS4/PS3, (B) PS4/PS3-dT20, or (C) PS4/PS3-dT25. 
fluorone (NSC5426) [40], a tricyclic planar compound (Figure 13A). The amino acid sequence of SaSsbC shares $36 \%$ identity with that of SaSsbA (Figure 1), particularly within the first 110 aa, which is the ssDNA-binding domain, and the model structure of SaSsbC resembles the crystal structure of SaSsbA possessing OB-folds (Figure 10). Thus, we tested whether SaSsbC could be inhibited by NSC5426, similar to SaSsbA. As shown in Figure 13B, NSC5426 can significantly inhibit SaSsbC binding to dT35 (Figure 13B). The $\mathrm{IC}_{50}$ value of SaSsbC for NSC5426, that is, the inhibitor concentration required to reduce the binding activity of the protein by $50 \%$, was $78 \pm 14 \mu \mathrm{M}$. Thus, SaSsbA inhibitor NSC5426 also inhibits SaSsbC.

We also tested whether or not the ssDNA-binding ability of SaSsbC can be inhibited by kaempferol, a flavonol with inhibitory activity on DnaB helicase binding to ssDNA [41]. Kaempferol also inhibits ssDNAdependent ATPase activity of PriA helicase and DnaB helicase [41-43]. In the presence of $50 \mu \mathrm{M}$ kaempferol, SaSsbC still bound to dT35 well (data not shown). Because of poor solubility of kaempferol, we could not conduct a test for possible inhibitory effect at higher

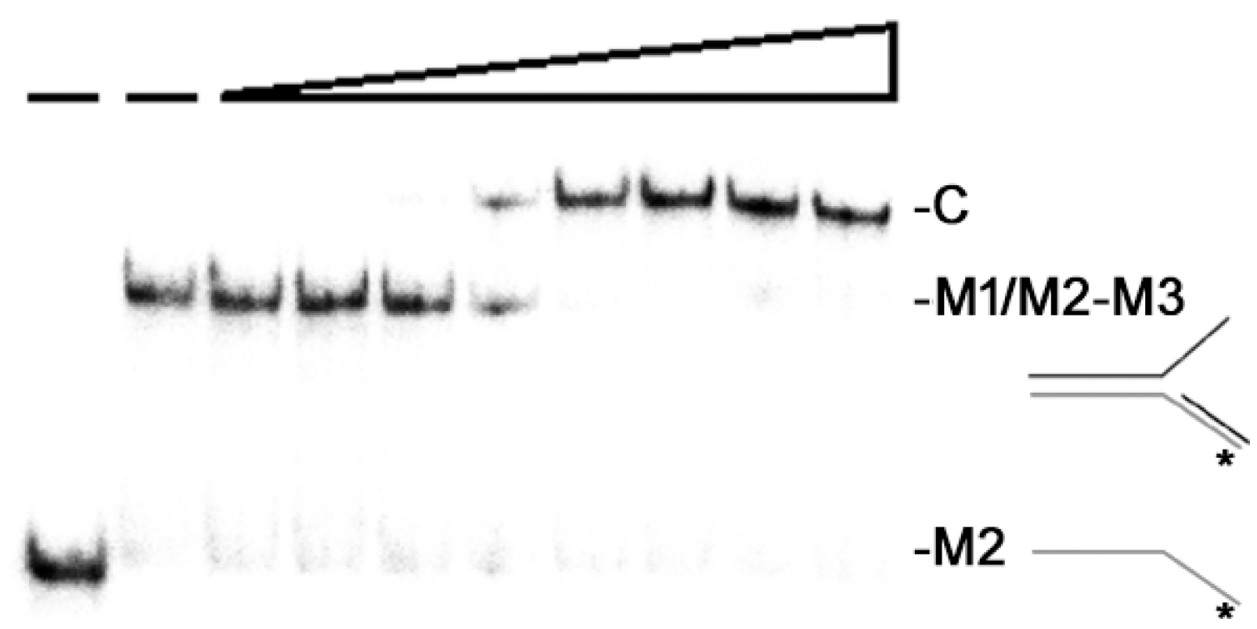

Figure 8: Binding analysis of SaSsbC to forked DNA. Protein $(0,0,0.02,0.039,0.078,0.1563,0.3125,0.625,1.25$, and $2.5 \mu \mathrm{M}$; tetramer) was incubated with $1.7 \mathrm{nM} \mathrm{M} 1 / \mathrm{M} 2-\mathrm{M} 3$ forked DNA substrate.
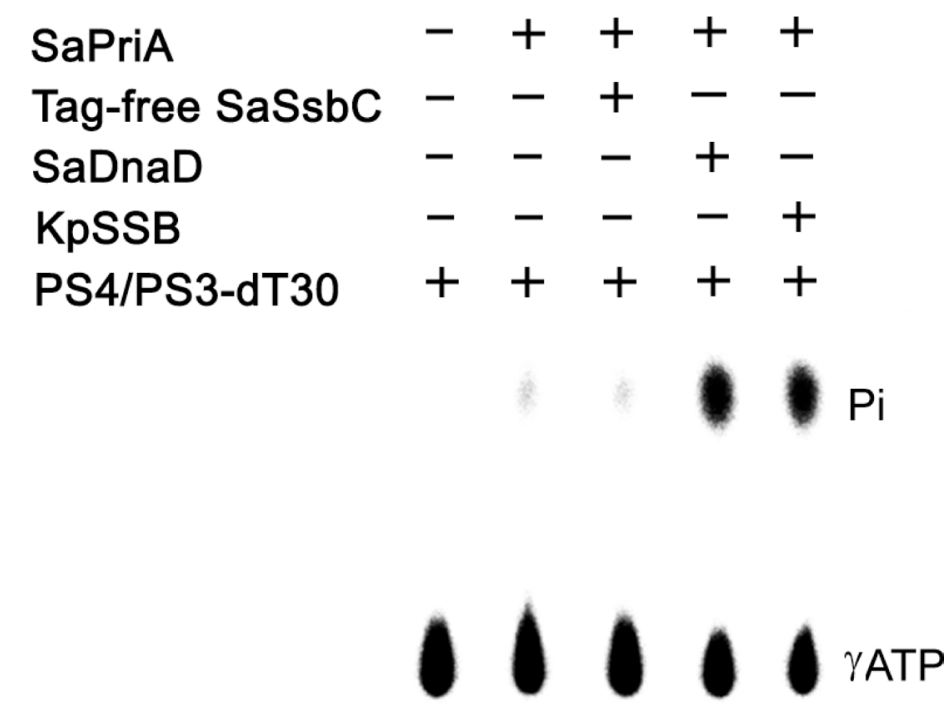

\section{Hydrolysis \% $\quad 0 \quad \begin{array}{llllll} & 4 & 3 & 40 & 37\end{array}$}

Figure 9: The ATPase activity of SaPriA did not change when acting with SaSsbC. SaPriAATPase assay was performed with $0.4 \mathrm{mM}[\gamma-32 \mathrm{P}]$ ATP, $0.12 \mu \mathrm{M}$ of SaPriA, and $0.1 \mu \mathrm{M}$ PS4/PS3-dT30 DNA substrate for $1 \mathrm{~h}$. To study the effect, tag-free SaSsbC (10 $\mu \mathrm{M})$, $\operatorname{KpSSB}(10 \mu \mathrm{M})$, or $\operatorname{SaDnaD}(10 \mu \mathrm{M})$ was added into the assay solution. Aliquots $(5 \mu \mathrm{L})$ were taken and spotted onto a polyethyleneimine cellulose thin-layer chromatography plate, which was subsequently developed in $0.5 \mathrm{M}$ formic acid and $0.25 \mathrm{M} \mathrm{LiCl}$ for $30 \mathrm{~m}$. Reaction products were visualized by autoradiography and quantified with a Phosphorimager. 
concentrations. Thus, kaempferol did not reach the level for sufficient inhibition of SaSsbC.

\section{DISCUSSION}

The discovery of small-molecule antibiotics for clinical use has been a seminal event in the field of infectious diseases [44]. S. aureus, a Gram-positive pathogen, exhibits a remarkable ability to develop antibiotic resistance, and few therapies are effective against methicillin-resistant S. aureus (MRSA) [45]. Considering that SSB is essential for all DNA-dependent cellular processes and that nucleic acid metabolism is one of the most basic biological functions, SSB should be a prime target in antibiotic development [46, 47]; therefore, SSBs become promising targets in antibiotic development [40]. Unlike $E$. coli, which produces only one type of SSB, $S$. aureus was indicated to express at least three SSBs in this study. SaSsbC, as well as SaSsbA and SaSsbB [40], may be a potential target against $S$. aureus growth and viability.

In silico analysis of the whole genome of $\mathrm{S}$. aureus revealed the presence of another SSB-like protein in addition to SaSsbA and SaSsbB (Figure 3). These three $\mathrm{SSB}$ in $\mathrm{S}$. aureus share an overall $36 \%$ sequence identity
(Figure 1), mostly being conserved in the first 110 aa, which is the N-terminal ssDNA-binding domain. In this study, we identified SaSsbC as a kind of SSB (Figure 4); however, its actual physiological role is yet to be understood. Gene map analysis showed that unlike E. coli $s s b$ gene located adjacent to $u v r A$ gene, the SaSsbC gene was shown to be flanked by the putative $S c e D$, the putative $Y w p F$, and $f a b Z$ genes, which code for a transglycosylase (231 aa), a hypothetical protein (167 aa), and a $\beta$-hydroxyacyl-ACP dehydratase (146 aa), respectively (Figure 3). If these genes belong to one operon or one regulatory control, $\mathrm{SaSsbC}$ may be regulated with these enzymes, which are involved in glycosidic linkages and fatty acid synthesis. However, the promoter for these genes is still unknown, and this hypothesized relationship must be further confirmed by a detailed transcription analysis.

$\mathrm{SaSsbC}$ exhibited a clear relationship with SSB at the amino acid sequence level, thereby suggesting that $\mathrm{SaSsbC}$ is a typical SSB protein in many respects. Results from the structural modeling (Figure 10) and mutational analyses (Figure 11) further indicated a similar ssDNAbinding mode between SaSsbC and EcSSB. Typical SSBs consist of an N-terminal OB-fold domain, a long proline/ glycine-rich flexible region, and a C-terminal acidic tail.
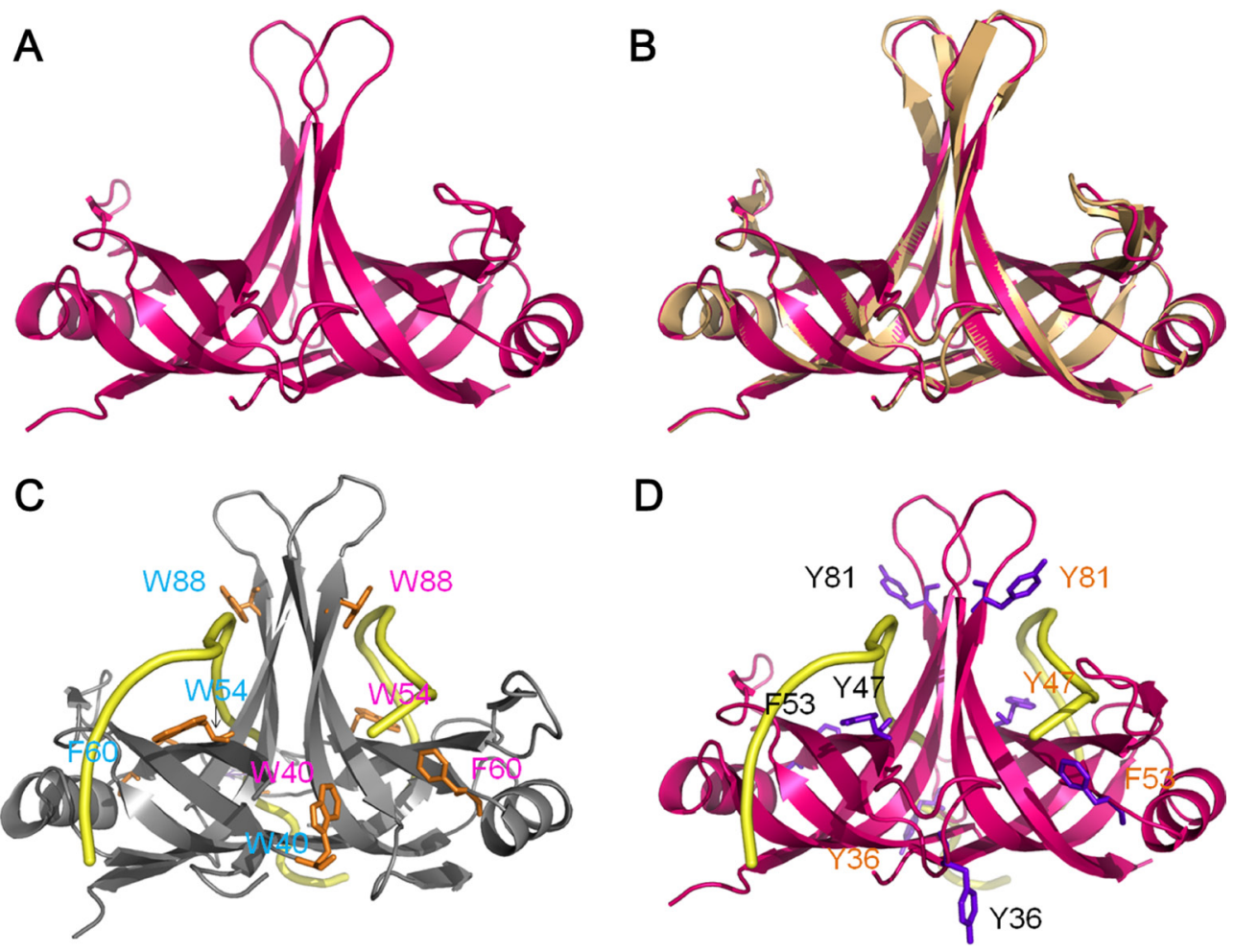

Figure 10: Structure modeling. (A) Structure modeling of the N-terminal domain (aa 1-103) of SaSsbC by SWISS-MODEL using SaSsbA as a template. For clarity, only a dimer of SaSsbC is shown. (B) Superposition of SaSsbC and SaSsbA. The N-terminal domains of $\mathrm{SaSsbC}$ and SaSsbA (PDB entry 5GXT; wheat) are similar. The structural model of SaSsbC (aa 1-103) reveals an OB-fold domain similar to SaSsbA. (C) Complexed crystal structure of EcSSB. Four essential aromatic residues, Trp40, Trp54, Phe60, and Trp88, participate in ssDNA binding (PDB entry 1EYG; gray). (D) ssDNA-binding mode of SaSsbC. Based on the structural similarity between SaSsbC and EcSSB, the corresponding residues in SaSsbC are Tyr36, Tyr47, Phe53, and Tyr81, which may play a similar role in ssDNA binding as those in EcSSB. 
Table 2: The [Protein $_{50}$ values of SaSsbC mutants as analyzed by EMSA

\begin{tabular}{lc}
\hline dT50 & Protein $_{\mathbf{5 0}}$ (nM) \\
\hline SaSsbC & $117 \pm 10$ \\
SaSsbC(Y36A) & $139 \pm 12$ \\
SaSsbC(Y47A) & $157 \pm 9$ \\
SaSsbC(F53A) & $202 \pm 26$ \\
SaSsbC(Y81A) & $278 \pm 18$ \\
\hline
\end{tabular}

[Protein $]_{50}$ was calculated from the titration curves of EMSA by determining the concentration of the protein (tetramers) needed to achieve the midpoint value for input DNA binding. Errors are standard deviations determined by three independent titration experiments.

The three SSBs in $S$. aureus also comprised an N-terminal OB-fold domain and a long flexible region, but their flexible regions contained very few proline and glycine residues. In addition, SaSsbC and SaSsbB showed no C-terminal acidic peptide tail (Figure 1), which interacts with the partner protein. SSB binds many DNA-binding proteins via the PXXP motifs and the $\mathrm{C}$-terminal acidic peptide tail such as RecG and PriA that constitute the SSB interactome $[1,2,9,10,48,49]$. The lack of the acidic peptide tail and PXXP motifs in SaSsbB and SaSsbC may rule out the possibility of binding to SaPriA. Thus, no stimulation occurred (Figure 9). We speculate that SsbC may play a different physiological role from the main SSB.

Unlike OB-fold protein PriB [50, 51], which can bind dsDNA and ssDNA comparably [52], SaSsbC was demonstrated to bind dsDNA only when these DNA substrates contain ssDNA tail longer than 25 mers
(Figure 7). Structurally, the N-terminal DNA binding domain of $\mathrm{SaSsbC}$ resembled PriB, in which the only significant difference was in the lengths of the $\beta 4$ and $\beta 5$ sheets. Whether the length of the $\beta 4$ and $\beta 5$ sheets in OB-fold proteins determines the ssDNA/dsDNA binding preference of SSB remains to be investigated. Many SSB proteins bind to ssDNA with some degree of positive cooperativity [11]. In this study, we found differing EMSA behaviors between SaSsbC and SSB proteins. SSB proteins form multiple distinct complexes with ssDNA of different lengths [12, 34-36, 53, 54], whereas SaSsbC binding to ssDNA dT25-dT60 formed only a single complex (Figure 4). Salt suppressed the binding of SaSsbC to ssDNA but did not change the complex number (Figure 5). The C-terminus in SSB can also interact with the OB fold and regulate the ssDNA-binding activity of SSB itself $[15,55]$. Thus, further studies are needed to determine whether the

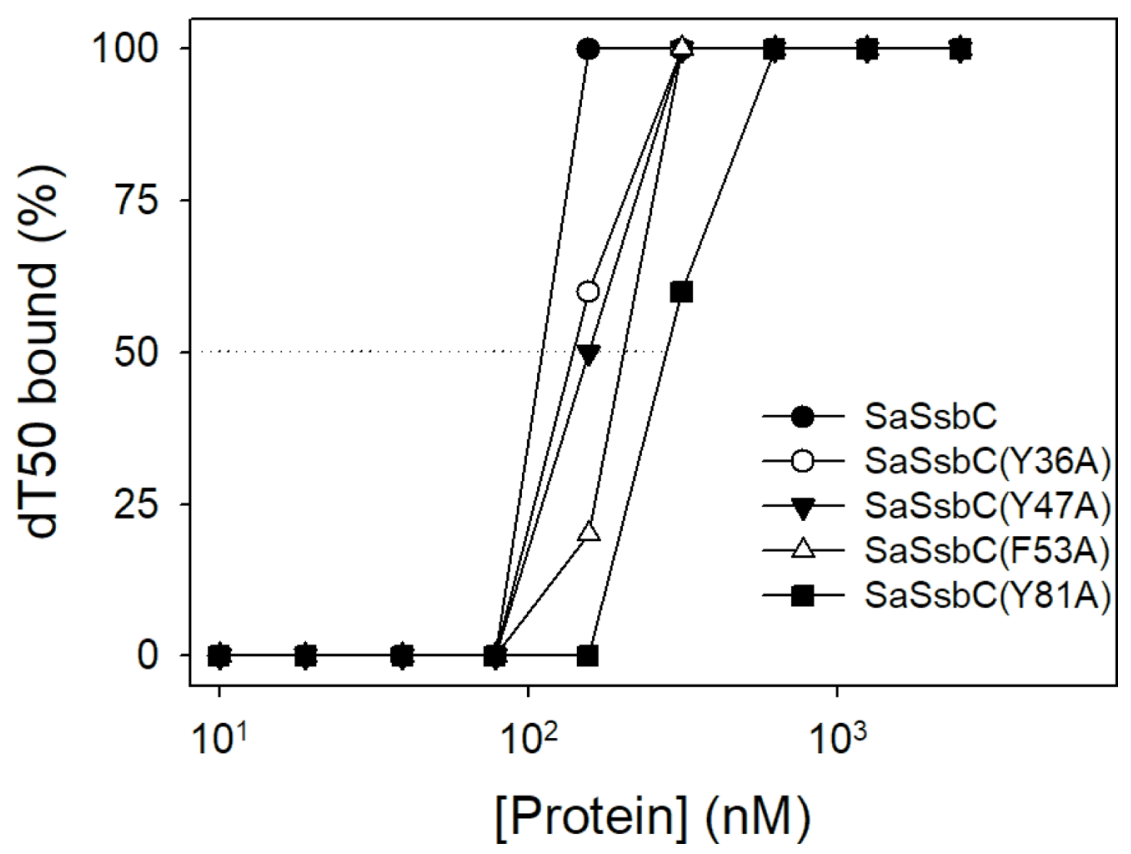

Figure 11: Mutational analysis of SaSsbC for ssDNA binding. Binding of SaSsbC mutant protein (Y36A, Y47A, F53A, and Y81A) to dT50. The mutant protein $(0,0.01,0.02,0.039,0.078,0.1563,0.3125,0.625,1.25$, and $2.5 \mu \mathrm{M}$; tetramer) was incubated with $1.7 \mathrm{nM}$ dT50. 
C-terminal domain of $\mathrm{SaSsbC}$, the most different between these SSB proteins, can change the EMSA patterns.

Flavonoids are the most common group of plant polyphenols with antioxidant, antiradical, anticancer, and antibacterial properties [56]. Some flavonoids are ATPaseinhibiting agents $[42,43]$. Flavonoid derivatives have been developed as therapeutic agents for cancer [57]. In this study, we found that the flavonol kaempferol can inhibit the ssDNA-binding activity of DnaB helicase [41] but not that of SaSsbC. NSC5426, an inhibitor on ssDNA-binding ability of SaSsbA, can also inhibit the activity of SaSsbC with the $\mathrm{IC}_{50}$ value of $78 \mu \mathrm{M}$. Thus, NSC5426 may be a competent "dirty drug", that is, a multi-target drug [58] against $S$. aureus. More studies are still needed for drug optimization and finding a new key target in $S$. aureus for antibiotic development.

\section{MATERIALS AND METHODS}

\section{Construction of plasmids for SaSsbC, tag-free SaSsbC, KpSSB, SaSsbA, SaDnaD, and SaPriA expression}

Construction of the SaSsbA [30], SaDnaD [31], SaPriA [42], and Klebsiella pneumoniae SSB (KpSSB) [36] expression plasmids has been reported. SAAV2152, the gene encoding a putative SSB-like protein (designated as $\mathrm{SaSsbC)}$, was amplified by PCR using the genomic

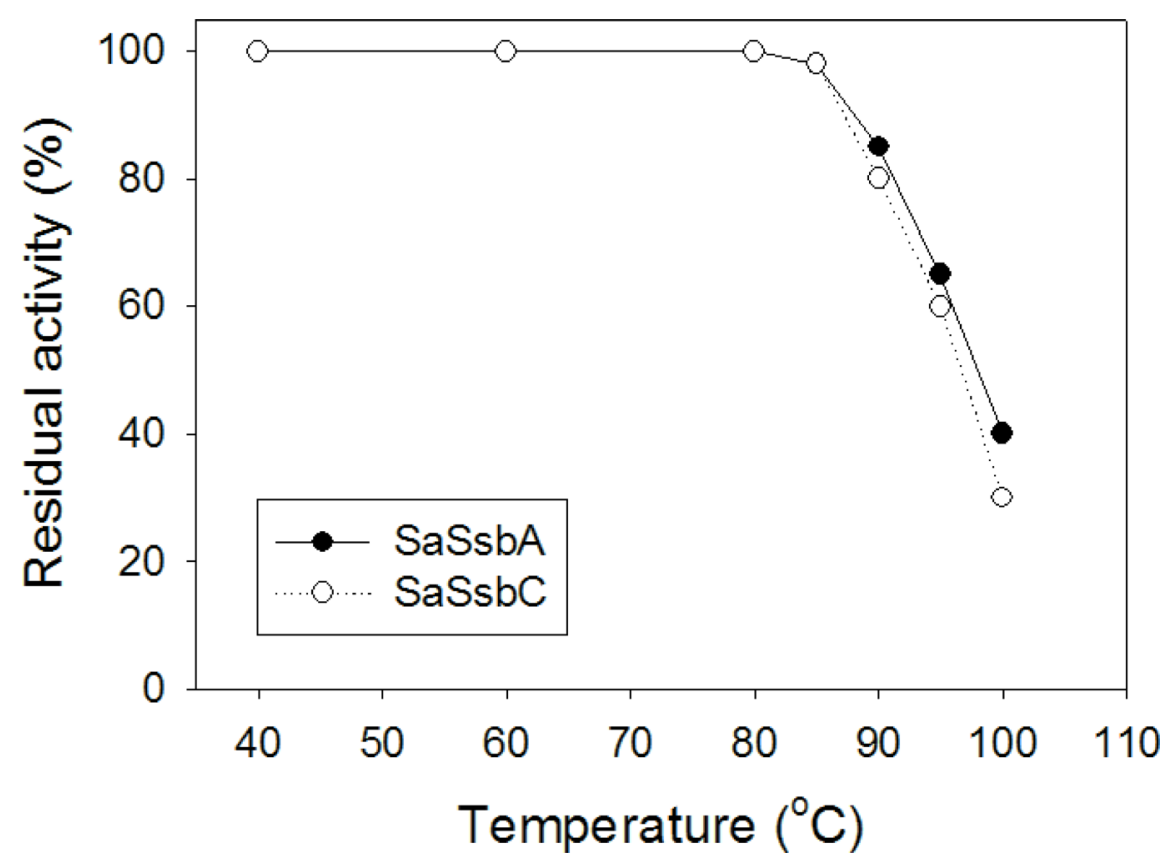

Figure 12: The thermostability of SaSsbC. Protein $(1 \mu \mathrm{M})$ was incubated at temperatures ranging from $40^{\circ} \mathrm{C}$ to $100^{\circ} \mathrm{C}$ for 30 min. The resultant protein solution was incubated at $25^{\circ} \mathrm{C}$ for $30 \mathrm{~min}$ with $1.7 \mathrm{nM}$ dT30 in a total volume of $10 \mu \mathrm{L}$ in $20 \mathrm{mM} \mathrm{Tris}-\mathrm{HCl}(\mathrm{pH} 8.0)$ and $100 \mathrm{mM} \mathrm{NaCl}$. The phosphor storage plate was scanned, and the data for complex and free DNA bands were digitized for quantitative analysis.<smiles>Cc1c2cc(O)c(=O)cc-2oc2cc(O)c(O)cc12</smiles>

NSC5426

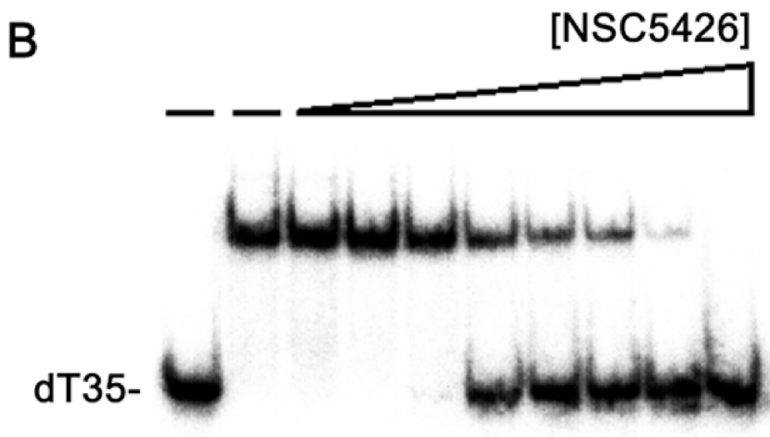

Figure 13: SaSsbA inhibitor NSC5426 inhibits SaSsbC. (A) Molecular structure of NSC5426. (B) IC $_{50}$ determination of NSC5426 for SaSsbC. Protein $(0.3 \mu \mathrm{M}$; tetramer) was incubated with $1.7 \mathrm{nM}$ dT35 and NSC5426 $(0,0,9,19,39,78,156,312,625$, and 1250 $\mu \mathrm{M})$ at $25^{\circ} \mathrm{C}$ for $30 \mathrm{~min}$ in a total volume of $10 \mu \mathrm{L}$ in $20 \mathrm{mM}$ Tris- $\mathrm{HCl}(\mathrm{pH} 8.0)$ and $100 \mathrm{mM} \mathrm{NaCl}$. 
DNA of $S$. aureus subsp. aureus ED98 as template. The forward and reverse primers were designed to introduce unique restriction sites, permitting the insertion of the amplified gene into the pET21b vector (Novagen Inc., Madison, WI, USA) for protein expression in E. coli. To obtain His tag-free SaSsbC, a fragment containing the coding sequence of SaSsbC and the stop codon was directly amplified and ligated into the pET21b vector. Primers used for construction of these plasmids are summarized in Table 3.

\section{Protein expression and purification}

Purification of the recombinant SaSsbA [30], SaDnaD [31], SaPriA [42], and KpSSB [36] has been reported. The recombinant SaSsbC was expressed and purified using the protocol described previously for PriB [51]. Briefly, E. coli BL21(DE3) cells were transformed with the expression vector and overexpression of the expression plasmids was induced by incubating with 1 $\mathrm{mM}$ isopropyl thiogalactopyranoside. The protein was purified from the soluble supernatant by $\mathrm{Ni}^{2+}$-affinity chromatography (HiTrap HP; GE Healthcare Bio-Sciences), eluted with Buffer A (20 mM Tris- $\mathrm{HCl}, 250 \mathrm{mM}$ imidazole, and $0.5 \mathrm{M} \mathrm{NaCl}, \mathrm{pH} 7.9$ ), and dialyzed against Buffer B (20 $\mathrm{mM}$ HEPES and $100 \mathrm{mM} \mathrm{NaCl}, \mathrm{pH}$ 7.0). Protein purity remained at $>97 \%$ as determined by SDS-PAGE (MiniPROTEAN Tetra System; Bio-Rad, CA, USA).

The recombinant tag-free $\mathrm{SaSsbC}$ was expressed and purified using the protocol described previously [53] for Pseudomonas aeruginosa SSB (PaSSB) and Salmonella enterica serovar Typhimurium LT2 SSB (StSSB) with the following modifications. The cells overexpressing the protein were chilled on ice, harvested by centrifugation, resuspended in Buffer C $(20 \mathrm{mM}$ Tris- $\mathrm{HCl}$ and $50 \mathrm{mM} \mathrm{NaCl}, \mathrm{pH}$ 7.9) and disrupted by sonication with ice cooling. The protein solution $(50 \mathrm{~mL})$ was precipitated from the supernatant of the cell lysate by incubation with $0.27 \mathrm{~g} / \mathrm{mL}$ of ammonium sulfate for $30 \mathrm{~min}$ and centrifugation at $20000 \mathrm{~g}$ for $10 \mathrm{~min}$. The pellets were washed twice with $2.0 \mathrm{~mL}$ of Buffer D (20 mM Tris- $\mathrm{HCl}, 50 \mathrm{mM} \mathrm{NaCl}$, and $1.2 \mathrm{M}$ ammonium sulfate, $\mathrm{pH}$ 7.9). After dialysis against Buffer $\mathrm{C}$, the protein solution applied to the Q column (GE Healthcare Bio-Sciences, Piscataway, NJ, USA) was eluted with a linear $\mathrm{NaCl}$ gradient from 0.1 to $0.6 \mathrm{M}$ with Buffer $\mathrm{C}$ using the AKTA-FPLC system (GE Healthcare BioSciences, Piscataway, NJ, USA). The peak fractions with the ssDNA binding activity were collected and dialyzed against Buffer E (20 mM potassium phosphate, $1 \mathrm{mM}$ EDTA, and $100 \mathrm{mM} \mathrm{NaCl}, \mathrm{pH}$ 7.0). The protein solution was then applied to the Heparin HP column (GE Healthcare Bio-Sciences, Piscataway, NJ, USA) and eluted with a linear $\mathrm{NaCl}$ gradient from 0.1 to $0.5 \mathrm{M}$ with Buffer E. The peak fractions from this chromatographic step with the ssDNA binding activity were collected and concentrated. Protein purity of tag-free $\mathrm{SaSsbC}$ remained at $>97 \%$ as determined by SDS-PAGE.

\section{Gel-filtration chromatography}

Gel-filtration chromatography was carried out by the AKTA-FPLC system (GE Healthcare Bio-Sciences, Piscataway, NJ, USA). In brief, purified SaSsbC (2 mg/mL) in Buffer B was applied to a Superdex 200 prep grade column (GE Healthcare Bio-Sciences, Piscataway, NJ, USA) equilibrated with the same buffer. The proteins were detected by measuring the absorbance at $280 \mathrm{~nm}$. The column was calibrated with proteins of known molecular weight: thyroglobulin (670 kDa), $\gamma$-globulin (158 kDa), albumin $(67 \mathrm{kDa})$, ovalbumin $(43 \mathrm{kDa})$, chymotrypsinogen $\mathrm{A}(25 \mathrm{kDa})$ and ribonuclease $\mathrm{A}(13.7 \mathrm{kDa})$.

\section{Electrophoretic mobility shift assay (EMSA)}

EMSA for SaSsbC was conducted using the protocol described previously for SSB [33]. Briefly, radiolabeling of various lengths of ssDNA oligonucleotides was carried out with $\left[\gamma^{32} \mathrm{P}\right]$ ATP $(6000 \mathrm{Ci} / \mathrm{mmol}$; PerkinElmer Life Sciences, Waltham, MA) and T4 polynucleotide kinase (Promega, Madison, WI, USA). The protein (0, 0.01, 0.02, $0.039,0.078,0.1563,0.3125,0.625,1.25$, and $2.5 \mu \mathrm{M}$; tetramer) was incubated for $30 \mathrm{~min}$ at $25^{\circ} \mathrm{C}$ with $1.7 \mathrm{nM}$ DNA substrates in a total volume of $10 \mu \mathrm{L}$ in $20 \mathrm{mM}$ Tris- $\mathrm{HCl} \mathrm{pH} 8.0$ and $100 \mathrm{mM} \mathrm{NaCl}$. Aliquots $(5 \mu \mathrm{l})$ were removed from each of the reaction solutions, and added to $2 \mu \mathrm{l}$ of gel-loading solution $(0.25 \%$ bromophenol blue and $40 \%$ sucrose). The resulting samples were resolved on a native $8 \%$ polyacrylamide gel at $4^{\circ} \mathrm{C}$ in TBE buffer ( $89 \mathrm{mM}$ Tris borate and $1 \mathrm{mM}$ EDTA) for $1 \mathrm{~h}$ at $100 \mathrm{~V}$, and were visualized by phosphorimaging. The phosphor storage plate was scanned, and the data for complex and free DNA bands were digitized for quantitative analysis. The ssDNA binding ability for the protein was estimated using linear interpolation from the protein concentration that binds $50 \%$ of the input DNA.

\section{Preparation of dsDNA substrate}

The double-stranded DNA substrates (dsDNA) were prepared with a radiolabeled PS4 strand (3'-GGG CTTAAGCCTATCGAGCCATGGG-5'; 25 mer) and an unlabeled PS3 strand (5'-CCCGAATTCGGATAGCTCG GTACCC-3') at a 1:1 concentration ratio. Unlabeled PS3dT5, PS3-dT10, PS3-dT15, PS3-dT20, and PS3-dT25 strands were also used with PS4 for preparation of dsDNA substrates. Each dsDNA substrate was formed in $20 \mathrm{mM}$ HEPES ( $\mathrm{pH} 7.0$ ) and $100 \mathrm{mM} \mathrm{NaCl}$, by brief heating at $95^{\circ} \mathrm{C}$ for $5 \mathrm{~min}$ and then followed by slow cooling to room temperature overnight. 
Table 3: Primers used for construction of plasmids

\begin{tabular}{ll}
\hline Oligonucleotide & Primer \\
\hline SaSsbC-NdeI-N & GGGAACATATGCTAAATAAAATCGTAA \\
SaSsbC-XhoI-C & CCATTCTCGAGAATTTCTAATAAGTCA \\
Tag-free SaSsbC-NdeI-N & GGGAACATATGCTAAATAAAATCGTAA \\
Tag-free SaSsbC-XhoI-C & CCATTCTCGAGTTAAATTTCTAATAAGTCA \\
SaSsbC(Y36A)-N & TGTTGCAACGCACCGAAATGCTAAAGATGAAAATGGAGAA \\
SaSsbC(Y36A)-C & GATTTCTCCATTTTCATCTTTAGCATTTCGGTGCGTTGCA \\
SaSsbC(Y47A)-N & ATGGAGAAATCGTCTGTGAT $\underline{\underline{G C} C T T A T T C T G T A A A G C A T T ~}$ \\
SaSsbC(Y47A)-C & CCAAATGCTTTACAGAATAAGGCATCACAGACGATTTCTC \\
SaSsbC(F53A)-N & GATTACTTATTCTGTAAAGCAGCTGGCAAGTTAGCTTCTA \\
SaSsbC(F53A)-C & TATTAGAAGCTAACTTGCCAGCTGCTTTACAGAATAAGTA \\
SaSsbC(Y81A)-N & GGTCAAATGAGATCAAGAAAGGCTGATAAAGACGGACAAA \\
SaSsbC(Y81A)-C & GTGTTTGTCCGTCTTTATCAGCCTTTCTTGATCTCATTTG \\
\hline
\end{tabular}

These plasmids were verified by DNA sequencing. Underlined nucleotides indicate the designated site for the restriction site or the mutation site.

\section{Preparation of forked DNA substrate}

The forked DNA substrate was prepared with a radiolabeled M2 strand (5'- AAGCTGTGGTGGTAACAA GTAGTGCCGGTGAAGCGGCGCACGAAAAACGCG AAAGCGTTTCACGATAAATGCGAAAAC-3'; 78 mer), an unlabeled M1 strand (5'- GTTTTCGCATTTATCGTG AAACGCTTTCGCGTTTTTCGTGCGCCGCTTCATGT ACACCGTTCATCTGTCCTCGTTCAAAGTTGGTCAG TT-3'; 90 mer), and an unlabeled M3 strand (5'-CCGGCA CTACTTGTTACCACCACAGCTT-3'; 28 mer) at a 1:1:1 concentration ratio. S1/M2-M3 forked DNA substrate was prepared with a radiolabeled M2 strand, an unlabeled S1 strand (5'-GTTTTCGCATTTATCGTGAAACGCTTTCG CGTTTTTCGTGCGCCGCTTCATGTACACCGTTCATC TGTCC-3'; 70 mer), and an unlabeled M3 strand at a 1:1:1 concentration ratio. These forked DNA substrates were formed in $20 \mathrm{mM}$ HEPES (pH 7.0) and $100 \mathrm{mM} \mathrm{NaCl}$, by brief heating at $95^{\circ} \mathrm{C}$ for $5 \mathrm{~min}$ and then followed by slow cooling to room temperature overnight.

\section{Chemical cross linking}

The oligomerization state of SaSsbC was analyzed by chemical cross linking using glutaraldehyde. SaSsbC $(2.5 \mu \mathrm{M})$ was incubated with increasing concentrations of glutaraldehyde $(0.1 \%$ to $5 \%)$ at $4{ }^{\circ} \mathrm{C}$ for $30 \mathrm{~min}$. The reactions were stopped by adding SDS sample buffer and were fractionated on Coomassie Blue-stained SDS-PAGE.

\section{ATPase assay \\ SaPriA ATPase assay [31] was performed with $0.4 \mathrm{mM}$ $\left[\gamma^{-32} \mathrm{P}\right]$ ATP and $0.12 \mu \mathrm{M}$ SaPriA in reaction buffer containing}

$40 \mathrm{mM}$ Tris (pH 8.0), $10 \mathrm{mM} \mathrm{NaCl}, 2 \mathrm{mM}$ DTT, $2.5 \mathrm{mM}$ $\mathrm{MgCl}_{2}$, and $0.1 \mu \mathrm{M}$ PS4/PS3-dT30 DNA substrate. Aliquots $(5 \mu \mathrm{L})$ were taken and spotted onto a polyethyleneimine cellulose thin-layer chromatography plate, which was subsequently developed in $0.5 \mathrm{M}$ formic acid and $0.25 \mathrm{M}$ $\mathrm{LiCl}$ for $30 \mathrm{~m}$. Reaction products were visualized by autoradiography and quantified with a phosphorimager.

\section{Site-directed mutagenesis}

$\mathrm{SaSsbC}$ mutants were generated according to the QuikChange Site-Directed Mutagenesis kit protocol (Stratagene, LaJolla, CA, USA) using the primers (Table 3) and wild-type plasmid pET21b-SaSsbC as template. The presence of the mutation was verified by DNA sequencing.

\section{Bioinformatics}

The amino acid sequences of 698 sequenced SSB homologs were aligned using ConSurf [32, 59]. The model of $\mathrm{SaSsbC}$ was built from the coordinates of 5XGT (crystal structure of SaSsbA) by using SWISS-MODEL, http:// swissmodel.expasy.org/. The structures were visualized by using the program PyMol.

\section{CONFLICTS OF INTEREST}

The author has no conflicts of interest.

\section{GRANT SUPPORT}

This research was supported by a grant from the Ministry of Science and Technology, Taiwan (MOST 1062320-B-040-004 to C.Y. Huang). 


\section{REFERENCES}

1. Richard DJ, Bolderson E, Khanna KK. Multiple human single-stranded DNA binding proteins function in genome maintenance: structural, biochemical and functional analysis. Crit Rev Biochem Mol Biol. 2009; 44:98-116.

2. Shereda RD, Kozlov AG, Lohman TM, Cox MM, Keck JL. SSB as an organizer/mobilizer of genome maintenance complexes. Crit Rev Biochem Mol Biol. 2008; 43:289-318.

3. Meyer RR, Laine PS. The single-stranded DNA-binding protein of Escherichia coli. Microbiol Rev. 1990; 54:342-380.

4. Dickey TH, Altschuler SE, Wuttke DS. Single-stranded DNA-binding proteins: multiple domains for multiple functions. Structure. 2013; 21:1074-1084.

5. Raghunathan S, Kozlov AG, Lohman TM, Waksman G. Structure of the DNA binding domain of E. coli SSB bound to ssDNA. Nat Struct Biol. 2000; 7:648-652.

6. Yang C, Curth U, Urbanke C, Kang C. Crystal structure of human mitochondrial single-stranded DNA binding protein at $2.4 \AA$ resolution. Nat Struct Biol. 1997; 4:153-157.

7. George NP, Ngo KV, Chitteni-Pattu S, Norais CA, Battista JR, Cox MM, Keck JL. Structure and cellular dynamics of Deinococcus radiodurans single-stranded DNA (ssDNA)binding protein (SSB)-DNA complexes. J Biol Chem. 2012; 287:22123-22132.

8. Witte G, Urbanke C, Curth U. Single-stranded DNAbinding protein of Deinococcus radiodurans: a biophysical characterization. Nucleic Acids Res. 2005; 33:1662-1670.

9. Bianco PR. The tale of SSB. Prog Biophys Mol Biol. 2017; 127:111-118.

10. Costes A, Lecointe F, McGovern S, Quevillon-Cheruel S, Polard P. The C-terminal domain of the bacterial SSB protein acts as a DNA maintenance hub at active chromosome replication forks. PLoS Genet. 2010; 6:e1001238.

11. Lohman TM, Ferrari ME. Escherichia coli single-stranded DNA-binding protein: multiple DNA-binding modes and cooperativities. Annu Rev Biochem. 1994; 63:527-570.

12. Olszewski M, Grot A, Wojciechowski M, Nowak M, Mickiewicz M, Kur J. Characterization of exceptionally thermostable single-stranded DNA-binding proteins from Thermotoga maritima and Thermotoga neapolitana. BMC Microbiol. 2010; 10:260.

13. Cadman CJ, Lopper M, Moon PB, Keck JL, McGlynn P. PriB stimulates PriA helicase via an interaction with singlestranded DNA. J Biol Chem. 2005; 280:39693-39700.

14. Cadman CJ, McGlynn P. PriA helicase and SSB interact physically and functionally. Nucleic Acids Res. 2004; 32:6378-6387.

15. Shishmarev D, Wang Y, Mason CE, Su XC, Oakley AJ, Graham B, Huber T, Dixon NE, Otting G. Intramolecular binding mode of the $\mathrm{C}$-terminus of Escherichia coli singlestranded DNA binding protein determined by nuclear magnetic resonance spectroscopy. Nucleic Acids Res. 2014; 42:2750-2757.

16. Kozlov AG, Cox MM, Lohman TM. Regulation of singlestranded DNA binding by the $\mathrm{C}$ termini of Escherichia coli single-stranded DNA-binding (SSB) protein. J Biol Chem. 2010; 285:17246-17252.

17. Singh A, Varshney U, Vijayan M. Structure of the second single stranded DNA binding protein $(\mathrm{SSBb})$ from Mycobacterium smegmatis. J Struct Biol. 2016; 196:448-454.

18. Singh A, Bhagavat R, Vijayan M, Chandra N. A comparative analysis of the DNA recombination repair pathway in mycobacterial genomes. Tuberculosis. 2016; 99:109-19.

19. Lindner C, Nijland R, van Hartskamp M, Bron S, Hamoen LW, Kuipers OP. Differential expression of two paralogous genes of Bacillus subtilis encoding single-stranded DNA binding protein. J Bacteriol. 2004; 186:1097-1105.

20. Ayora S, Carrasco B, Cardenas PP, Cesar CE, Canas C, Yadav T, Marchisone C, Alonso JC. Double-strand break repair in bacteria: a view from Bacillus subtilis. FEMS Microbiol Rev. 2011; 35:1055-1081.

21. Paradzik T, Ivic N, Filic Z, Manjasetty BA, Herron P, Luic M, Vujaklija D. Structure-function relationships of two paralogous single-stranded DNA-binding proteins from Streptomyces coelicolor: implication of $\mathrm{SsbB}$ in chromosome segregation during sporulation. Nucleic Acids Res. 2013; 41:3659-3672.

22. Yadav T, Carrasco B, Myers AR, George NP, Keck JL, Alonso JC. Genetic recombination in Bacillus subtilis: a division of labor between two single-strand DNA-binding proteins. Nucleic Acids Res. 2012; 40:5546-5559.

23. Attaiech L, Olivier A, Mortier-Barriere I, Soulet AL, Granadel C, Martin B, Polard P, Claverys JP. Role of the single-stranded DNA-binding protein $\mathrm{SsbB}$ in pneumococcal transformation: maintenance of a reservoir for genetic plasticity. PLoS Genet. 2011; 7:e1002156.

24. Windgassen TA, Wessel SR, Bhattacharyya B, Keck JL. Mechanisms of bacterial DNA replication restart. Nucleic Acids Res. 2017; https://doi.org/10.1093/nar/gkx1203.

25. Sandler SJ, Marians KJ. Role of PriA in replication fork reactivation in Escherichia coli. J Bacteriol. 2000; 182:9-13.

26. Marians KJ. PriA-directed replication fork restart in Escherichia coli. Trends Biochem Sci. 2000; 25:185-189.

27. Ng JY, Marians KJ. The ordered assembly of the phiX174type primosome. I. Isolation and identification of intermediate protein-DNA complexes. J Biol Chem. 1996; 271:15642-15648.

28. Allen GC Jr, Dixon NE, Kornberg A. Strand switching of a replicative DNA helicase promoted by the E. coli primosome. Cell. 1993; 74:713-722.

29. Ouzounis CA, Blencowe BJ. Bacterial DNA replication initiation factor priA is related to proteins belonging to the ‘DEAD-box' family. Nucleic Acids Res. 1991; 19:6953. 
30. Huang YH, Guan HH, Chen CJ, Huang CY. Staphylococcus aureus single-stranded DNA-binding protein SsbA can bind but cannot stimulate PriA helicase. PLoS One. 2017; 12:e0182060.

31. Huang YH, Lien Y, Huang CC, Huang CY. Characterization of Staphylococcus aureus primosomal DnaD protein: highly conserved C-terminal region is crucial for ssDNA and PriA helicase binding but not for DnaA protein-binding and selftetramerization. PLoS One. 2016; 11:e0157593.

32. Landau M, Mayrose I, Rosenberg Y, Glaser F, Martz E, Pupko T, Ben-Tal N. ConSurf 2005: the projection of evolutionary conservation scores of residues on protein structures. Nucleic Acids Res. 2005; 33:W299-302.

33. Huang CY. Determination of the binding site-size of the protein-DNA complex by use of the electrophoretic mobility shift assay. In: Innocenti A, editor. Stoichiometry and Research - The Importance of Quantity in Biomedicine. 2012; Rijeka, Croatia, InTech Press.

34. Jan HC, Lee YL, Huang CY. Characterization of a singlestranded DNA-binding protein from Pseudomonas aeruginosa PAO1. Protein J. 2011; 30:20-26.

35. Huang YH, Lee YL, Huang CY. Characterization of a single-stranded DNA binding protein from Salmonella enterica serovar Typhimurium LT2. Protein J. 2011; 30:102-108.

36. Huang YH, Huang CY. Characterization of a single-stranded DNA-binding protein from Klebsiella pneumoniae: mutation at either $\operatorname{Arg} 73$ or Ser76 causes a less cooperative complex on DNA. Genes Cells 2012; 17:146-157.

37. Lohman TM, Tomko EJ, Wu CG. Non-hexameric DNA helicases and translocases: mechanisms and regulation. Nat Rev Mol Cell Biol. 2008; 9:391-401.

38. Arnold K, Bordoli L, Kopp J, Schwede T. The SWISSMODEL workspace: a web-based environment for protein structure homology modelling. Bioinformatics 2006; 22:195-201.

39. Nowak M, Olszewski M, Spibida M, Kur J. Characterization of single-stranded DNA-binding proteins from the psychrophilic bacteria Desulfotalea psychrophila, Flavobacterium psychrophilum, Psychrobacter arcticus, Psychrobacter cryohalolentis, Psychromonas ingrahamii, Psychroflexus torquis, and Photobacterium profundum. BMC Microbiol. 2014; 14:91.

40. Glanzer JG, Endres JL, Byrne BM, Liu S, Bayles KW, Oakley GG. Identification of inhibitors for single-stranded DNA-binding proteins in eubacteria. J Antimicrob Chemother. 2016; 71:3432-3440.

41. Lin HH, Huang CY. Characterization of flavonol inhibition of DnaB helicase: real-time monitoring, structural modeling, and proposed mechanism. J Biomed Biotechnol. 2012; 2012:735368.

42. Huang YH, Huang CC, Chen CC, Yang KJ, Huang CY. Inhibition of Staphylococcus aureus PriA helicase by flavonol kaempferol. Protein J. 2015; 34:169-172.
43. Chen CC, Huang CY. Inhibition of Klebsiella pneumoniae DnaB helicase by the flavonol galangin. Protein J. 2011; 30:59-65.

44. Koul A, Arnoult E, Lounis N, Guillemont J, Andries K. The challenge of new drug discovery for tuberculosis. Nature. 2011; 469:483-490.

45. Koyama N, Inokoshi J, Tomoda H. Anti-infectious agents against MRSA. Molecules. 2012; 18:204-224.

46. Voter AF, Killoran MP, Ananiev GE, Wildman SA, Hoffmann FM, Keck JL. A high-throughput screening strategy to identify inhibitors of SSB protein-protein interactions in an academic screening facility. SLAS Discov. 2018; 23:94-101.

47. Marceau AH, Bernstein DA, Walsh BW, Shapiro W, Simmons LA, Keck JL. Protein interactions in genome maintenance as novel antibacterial targets. PLoS One. 2013; 8: e58765.

48. Bianco PR, Pottinger S, Tan HY, Nguyenduc T, Rex K, Varshney U. The IDL of E. coli SSB links ssDNA and protein binding by mediating protein-protein interactions. Protein Sci. 2017; 26:227-241.

49. Bianco PR, Lyubchenko YL. SSB and the RecG DNA helicase: an intimate association to rescue a stalled replication fork. Protein Sci. 2017; 26:638-649.

50. Liu JH, Chang TW, Huang CY, Chen SU, Wu HN, Chang MC, Hsiao CD. Crystal structure of PriB, a primosomal DNA replication protein of Escherichia coli. J Biol Chem. 2004; 279:50465-50471.

51. Huang CY, Hsu CH, Sun YJ, Wu HN, Hsiao CD. Complexed crystal structure of replication restart primosome protein PriB reveals a novel single-stranded DNA-binding mode. Nucleic Acids Res. 2006; 34:3878-3886.

52. Huang YH, Lo YH, Huang W, Huang CY. Crystal structure and DNA-binding mode of Klebsiella pneumoniae primosomal PriB protein. Genes Cells. 2012; 17:837-849.

53. Huang YH, Huang CY. C-terminal domain swapping of SSB changes the size of the ssDNA binding site. Biomed Res Int. 2014; 2014:573936.

54. Olszewski M, Mickiewicz M, Kur J. Two highly thermostable paralogous single-stranded DNA-binding proteins from Thermoanaerobacter tengcongensis. Arch Microbiol. 2008; 190:79-87.

55. Kozlov AG, Jezewska MJ, Bujalowski W, Lohman TM. Binding specificity of Escherichia coli single-stranded DNA binding protein for the chi subunit of DNA pol III holoenzyme and PriA helicase. Biochemistry. 2010; 49:3555-3566.

56. Ross JA, Kasum CM. Dietary flavonoids: bioavailability, metabolic effects, and safety. Annu Rev Nutr. 2002; 22:19-34.

57. Teillet F, Boumendjel A, Boutonnat J, Ronot X. Flavonoids as RTK inhibitors and potential anticancer agents. Med Res Rev. 2008; 28:715-745. 
58. Huang CY. Inhibition of a putative dihydropyrimidinase from Pseudomonas aeruginosa PAO1 by flavonoids and substrates of cyclic amidohydrolases. PLoS One. 2015; 10: $\mathrm{e} 0127634$.
59. Ho YY, Huang YH, Huang CY. Chemical rescue of the posttranslationally carboxylated lysine mutant of allantoinase and dihydroorotase by metal ions and short-chain carboxylic acids. Amino Acids. 2013; 44:1181-1191. 